\title{
Effect of Anisotropic Flow of Water on Consolidation Behaviour of Silty-Clay Soil
}

\author{
Arpan Laskar ${ }^{\# 1}$, Sujit Kumar Pal ${ }^{* 2}$ \\ Civil Engineering Department, NIT Agartala, India, 799046 \\ Email: ${ }^{1}$ arpan2k8@yahoo.co.in \\ 2skpal1963@gmail.com
}

\begin{abstract}
In the traditional method of determination of consolidation properties of soil based on oedometer test, it is assumed that the flow of water occurs in the vertical direction only. Radial flow of water is restrained in oedometer test. In this study an experimental setup is fabricated to measure consolidation properties of soil by considering different anisotropic flow of water through soil. In some of the practical cases we may not have radial flow of water throughout the radial directions and in those cases it is essential to consider anisotropic radial flow of water to predict consolidation characteristics of soil for consequent in-situ conditions. In this study an anisotropic flow of water has been considered at the time of experimental determination of consolidation characteristics of soil. From experimental results it is observed that the rate of extraction of water get increase when radial flow take under consideration and the anisotropic radial flow have an immense effect on the co-efficient of consolidation of soil.
\end{abstract}

Keywords-Consolidation, Oedometer, Radial flow, Anisotropic, Co-efficient of consolidation

\section{INTRODUCTION}

In case of traditional one-dimensional consolidation test, horizontal drainage of water is restrained by providing an impermeable desiccation all the way through the radial direction. As the radial drainage do not take under consideration at the time of consolidation of soil sample under the vertical load, the one-dimensional consolidation test does not providea representative result of actual field conditions. The 1-D Oedometer test apparatus having lateral confinement is considered to be representative of the in-situ soil conditions. There are so many practical problems which are seriously different from this assumption and need to consider anisotropic flow of water at the time of assessing consolidation behaviour of soil.Terzaghi [1] presented his first onedimensional consolidation concept where the authors have considered that the soil samples are desiccated by adjacent elements which are subjected to same state of stresses. The general theory of three-dimensional consolidation was first introduced by Biot [2] in which coupling between solid and fluid was considered. In the past few decades, many investigators had been developed different analytical solutions based on Biot's consolidation theory [2]. Biotstudied the theory of elasticity and consolidation for a porous anisotropic solid. This study extended the theory to the most general case of anisotropy. In this study authors introduced some physical assumptions that the skeleton is purely elastic and contains a compressible viscous fluid. Ai et al. [3] studied 3-D consolidation of multilayered porous medium with anisotropic permeability and compressible pore fluid by using the transfer matrix method. By analysis of a five-layered porous medium shows that the layered characteristic, the anisotropy of permeability and the compressibility of pore fluid of porous medium have great influences on the surface settlement.Hwang and Witczak [4] developed a numerical procedure for probabilistic solution of consolidation of soils with multi-dimensional soil variability and water flow.

All the previous investigations of three-dimensional consolidation were analytical or numerical based and boundary assumptions were not as replicating to the field conditions. Hence, it is important to develop an experimental solution for three-dimensional consolidation problems having different conditions of flow of water.

\section{AIM AND SCOPE OF THE STUDY}

Anisotropic permeability does not have any effect on the amount of settlement but it has an immense effect on the rate of settlement. The aim of this study is to resolve the effects of anisotropic flow of water on consolidation behaviour of soil, specifically the rate of consolidation. In this study three different anisotropic flow conditions are considered and studied the effects of these anisotropic flows on three-dimensional consolidation of silty-clay soil. Due to having anisotropic permeability and free radial movement of soil particles along with the progress of consolidation, it may be more simulating to the three-dimensional consolidation of soil in the field. 


\section{DIFFERENT BOUNDARY CONDITIONS OF THE TESTS SIMULATING TO FIELD CONDITIONS}

Three different anisotropic flow condition cases are studied in this paper as shown in Fig. 1. Case I: flow of water is same through all the directions (isotropic flow).Case II: flow occurs through vertical up and down directions only, (anisotropic flow)and Case III: the direction of flow only occurs through upper vertical direction (anisotropic flow).

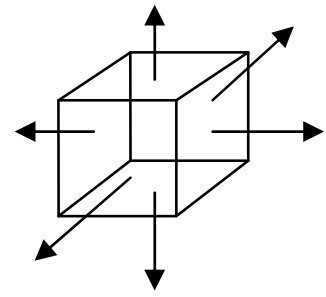

Case I

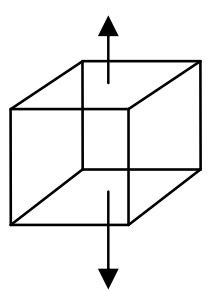

Case II

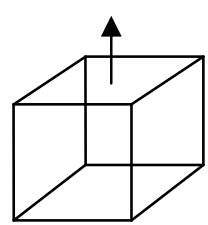

Case III

Fig. 1. Three different flow conditions under 3-D consolidation test

\section{THEORETICAL CONSIDERATIONS}

Convenient assumptions of present three- dimensional consolidation test are as follows:

1. The soil is homogeneous and the soil properties are isotropic.

2. The soil is two faced saturated.

3. Vertical and horizontal movements of soil particles are allowed during the process of consolidation.

4. The compression of the soil is due to the change in volume only, which in turn, is due to the squeezing out of water from void space in vertical as well as horizontal direction.

5. Darcy's law is valid.

6. In case of plastic settlement, if all the soil particles are interconnected then vertical movement of soil particles occur due to horizontal movements of underneath soil particles. Without horizontal movement of underneath soil particles there will be no vertical movement of top soil particles.

7. Lower boundary of stress remains constant throughout the consolidation process.

\section{TESTING MATERIAL AND PROGRAMME}

Experiments are conducted with a silty-clay soil. Different properties of those soils are tabulated in Table I. This soil sample is compacted to its maximum dry density at standard Proctor energy and saturated it over some period before performing the test and this soil sample is considered as an ideal two face soil system during the test.

TABLE I. Properties of Soil

\begin{tabular}{|l|c|}
\hline Soil Properties & Silty-clay soil \\
\hline Specific gravity & 2.50 \\
\hline Liquid limit (\%) & 53.35 \\
\hline Plastic limit (\%) & 29.32 \\
\hline Plasticity index (\%) & 24.03 \\
\hline & Sand: 4.86 \\
Grain size (\%) & Silt: 41.46 \\
& Clay: 53.68 \\
\hline Optimum moisture content (OMC) $(\%)$ & 25.75 \\
\hline Maximum dry density (MDD) (gm/(cm $\left.{ }^{3}\right)$ & 1.56 \\
\hline
\end{tabular}




\section{TESTING EQUIPMENT USED TO PERFORM THE TESTS UNDER DIFFERENT BOUNDARY CONDITIONS}

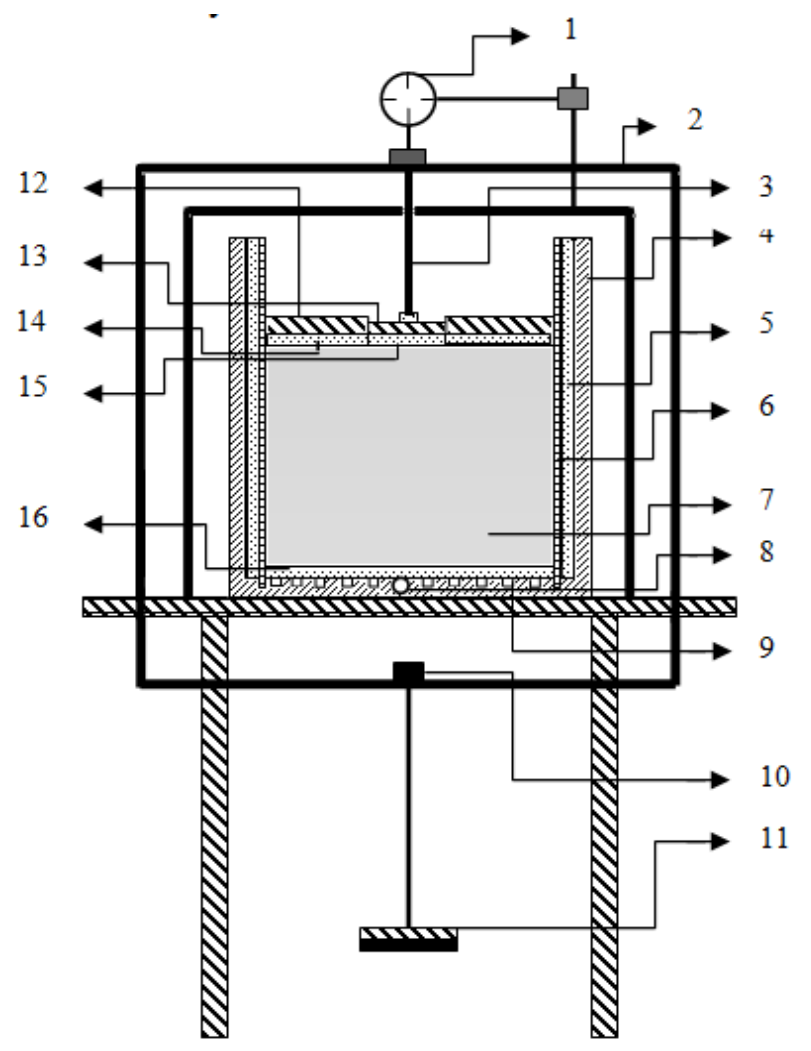

1) Dial gauge

2) Loading frame

3) Plunger

4) Consolidation tank

5) Side porous stone plate

6) Perforated cast iron box

7) Soil sample

8) Outlet

9) Bottom thread connected to outlet

10) Lever loading system

11) Load

12) Initial sitting loading plate with $61 \mathrm{~mm}$ diameter centre hole

13) Perforated loading plate

14) Top porous stone bellow the initial sitting loading plate with $61 \mathrm{~mm}$ diameter centre hole

15) Top porous stone bellow the perforated loading plate

16) Bottom porous stone

Fig. 2. Cross-sectional view of three-dimensional consolidation apparatus

\section{SPECIMEN PREPARATION AND TEST PROCEDURE}

The soils used for the experiment is silty-clay soil of Tripura, India. The properties of the soil are listed in Table I.Soil sample is compacted by standard Proctor energy at its maximum dry density (MDD) in porous cast iron box in three layers and the inner sides of the box are covered by filter paper before compacting the soil sample. Aftercompacting the soil sample, porous box with the sample has been placed over the bottom porous stone in consolidation tank. Four consecutive sides of the porous cast iron box are covered by porous stone plates as shown in Fig. 2. A cast iron plate having $61 \mathrm{~mm}$ diameter central hole is placed over the soil sample to apply initial seating load of $0.05 \mathrm{~kg} / \mathrm{cm}^{2}$. A filter paper, a porous stone and a perforated loading plate of $60 \mathrm{~mm}$ diameter has been inserted consecutively through the $61 \mathrm{~mm}$ diameter centre hole of cast iron plate. Load is applied by lever loading frame system to the top perforated loading plate of $60 \mathrm{~mm}$ diameter through a plunger. Initially $0.05 \mathrm{~kg} / \mathrm{cm}^{2}$ stress is applied as a seating load and kept it for 48 hours. After 48 hours, the specimen is allowed to consolidate under a number of increments of vertical pressure, such as $0.5 \mathrm{~kg} / \mathrm{cm}^{2}, 1.00 \mathrm{~kg} / \mathrm{cm}^{2}, 2.00$ $\mathrm{kg} / \mathrm{cm}^{2}, 4.00 \mathrm{~kg} / \mathrm{cm}^{2}$ and $8.00 \mathrm{~kg} / \mathrm{cm}^{2}$ vertical pressure and each pressure increment is maintained constant for 24 hours. With the application of vertical pressure on soil, the vertical settlement of perforated loading plate is measured by a strain gauge. Strain gauge readings are taken after the application of each vertical stress increment at the following total elapsed time- $0.25,1.00,2.25,4.00,6.25,9.00,12.25,16.00,20.25,25.00$, $36.00,49.00,64.00,100.00,144.00,196.00,225.00,256.00,1440.00$ minutes. Tests have been conducted by new 3-D consolidation set-up and traditional 1-D oedometer [5]withthe same size of loading plate (i.e. $60 \mathrm{~mm}$ diameter).

\section{EXPERIMENTAL RESULTS AND ANALYSIS}

Experiments are conducted on a silty-clay soil samples. The physical properties along with maximum dry density (MDD) and optimum moisture content (OMC) obtained by standard Proctor compaction test of the soil are listed in Table I. Conventional one-dimensional consolidation tests and newly developed three-dimensional consolidation tests are conducted on this soil, which are compacted at MDD and OMC. Table II shows the variation of void ratio with the change of vertical stress for 1-D oedometer test and Table IIIshows the variation of void ratio with the change of vertical stress for 3-D consolidation under different anisotropic flow conditions. Tables IV and V presented the change of compression index of silty-clay soil obtained from 1-D oedometer and newly developed 3-D consolidometertests. Table VIshows the comparison of rate of consolidation of silty-clay soil by using 1-D oedometer and newly developed 3-D consolidometer apparatus. 
TABLE II. Variationof Void Ratio with Change of Vertical Stress for Silty-Clay by Traditional 1-D Oedometer Test Apparatus

\begin{tabular}{|c|c|c|}
\hline Material & Pressure range $\mathbf{( k g / \mathbf { c m } ^ { 2 }}$ ) & Void ratio (e) \\
\hline \multirow{4}{*}{ Silty-clay soil } & $0.5-1.0$ & 0.597 \\
\cline { 2 - 3 } & $1.0-2.0$ & 0.564 \\
\cline { 2 - 3 } & $2.0-4.0$ & 0.525 \\
\cline { 2 - 3 } & $4.0-8.0$ & 0.472 \\
\hline
\end{tabular}

TABLE III. Variationof Void Ratio with Change of Vertical Pressure for Silty-Clay Soil by 3-D Consolidometer Test Apparatus under Different Flow Conditions

\begin{tabular}{|c|c|c|}
\hline \multirow{3}{*}{ Material } & Pressure ranges $\left(\mathbf{k g} / \mathbf{c m}^{2}\right)$ & $\begin{array}{c}\text { Void ratio (e) } \\
\text { (For Cases-I, II and III of Fig.1) }\end{array}$ \\
\hline \multirow{3}{*}{ Silty-clay soil } & $0.5-1.0$ & 0.652 \\
\cline { 2 - 3 } & $1.0-2.0$ & 0.635 \\
\cline { 2 - 3 } & $2.0-4.0$ & 0.599 \\
\cline { 2 - 3 } & $4.0-8.0$ & 0.509 \\
\hline
\end{tabular}

TABLE IV. Values of Compression Index of Silty-Clay Soil by Traditional 1-D Oedometer Test Apparatus

\begin{tabular}{|c|c|c|}
\hline Material & Pressure ranges $\left.\mathbf{( k g / \mathbf { c m } ^ { 2 }}\right)$ & Compression index $\left(\mathbf{C}_{\mathbf{c}}\right)$ \\
\hline \multirow{4}{*}{ Silty-clay soil } & $0.5-1.0$ & 0.080 \\
\cline { 2 - 3 } & $1.0-2.0$ & 0.109 \\
\cline { 2 - 3 } & $2.0-4.0$ & 0.129 \\
\cline { 2 - 3 } & $4.0-8.0$ & 0.176 \\
\hline
\end{tabular}

TABLE V. Values of Compression Index of Silty-Clay Soil by Present 3-D Consolidometer Test Apparatus

\begin{tabular}{|c|c|c|}
\hline Material & Pressure ranges $\left(\mathbf{k g} / \mathbf{c m}^{2}\right)$ & Compression index $\left(\mathbf{C}_{\mathbf{c}}\right)$ \\
\hline \multirow{4}{*}{ Silty-clay soil } & $0.5-1.0$ & 0.023 \\
\cline { 2 - 3 } & $1.0-2.0$ & 0.056 \\
\cline { 2 - 3 } & $2.0-4.0$ & 0.119 \\
\cline { 2 - 3 } & $4.0-8.0$ & 0.300 \\
\hline
\end{tabular}

TABLE VI. Values of Coefficient of Consolidation of Silty-Clay Soil by Using Traditional 1-D Oedometer Test Apparatus

\begin{tabular}{|c|c|c|c|c|c|}
\hline Material & \multirow{2}{*}{$\begin{array}{c}\text { Pressure ranges } \\
\left(\mathbf{k g} / \mathbf{c m}^{\mathbf{2}}\right)\end{array}$} & 1-D consolidation & \multicolumn{3}{|c|}{ 3-D consolidation } \\
\cline { 3 - 6 } & & $\mathbf{c}_{\mathbf{v} 1} \times \mathbf{1 0}^{-4} \mathbf{( \mathbf { c m } ^ { 2 } / \mathbf { s e c } )}$ & \multicolumn{3}{|c|}{$\mathbf{c}_{\mathbf{v} 3} \times \mathbf{1 0}^{-\mathbf{4}} \mathbf{( \mathbf { c m } ^ { 2 } / \mathbf { s e c } )}$} \\
\cline { 4 - 6 } & & & Case-I & Case-II & Case-III \\
\hline \multirow{3}{*}{ Silty-clay soil } & $0.5-1.0$ & 3.31 & 103.72 & 70.99 & 58.48 \\
\cline { 2 - 6 } & $1.0-2.0$ & 4.57 & 187.07 & 129.33 & 109.14 \\
\cline { 2 - 6 } & $2.0-4.0$ & 4.66 & 430.16 & 234.84 & 219.70 \\
\cline { 2 - 6 } & $4.0-8.0$ & 7.54 & 461.88 & 359.00 & 330.90 \\
\hline
\end{tabular}




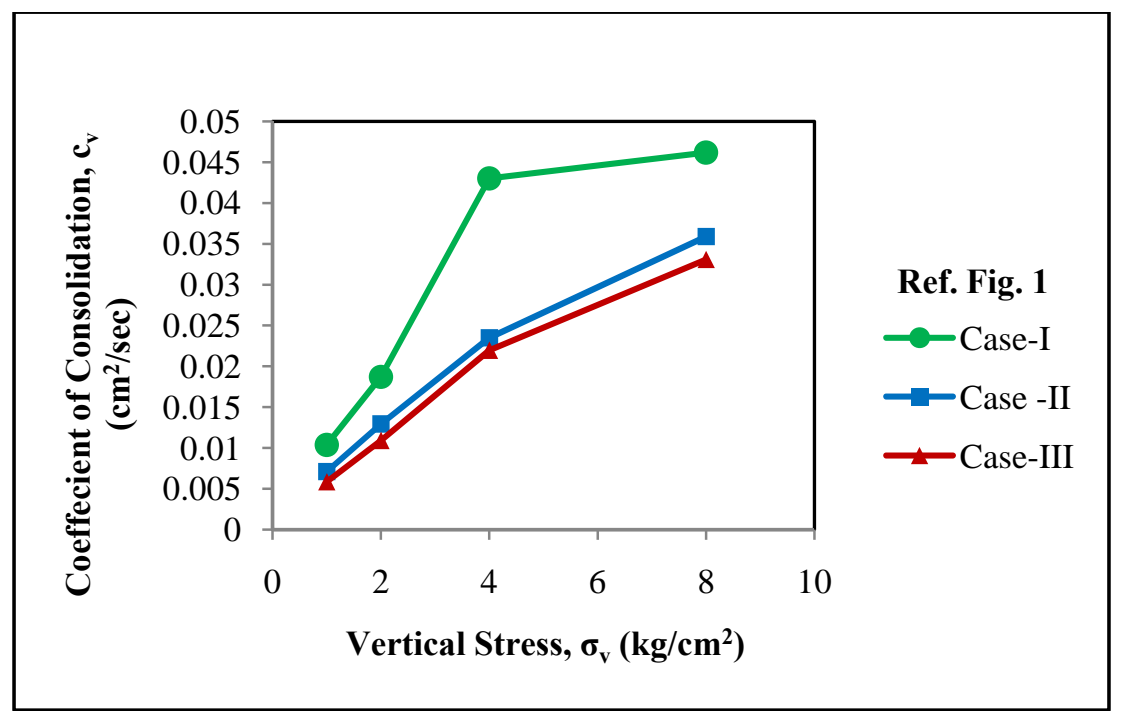

Fig. 3. Coefficient of consolidation of silty-clay soil under different flow conditions by 3-D consolidometer apparatus

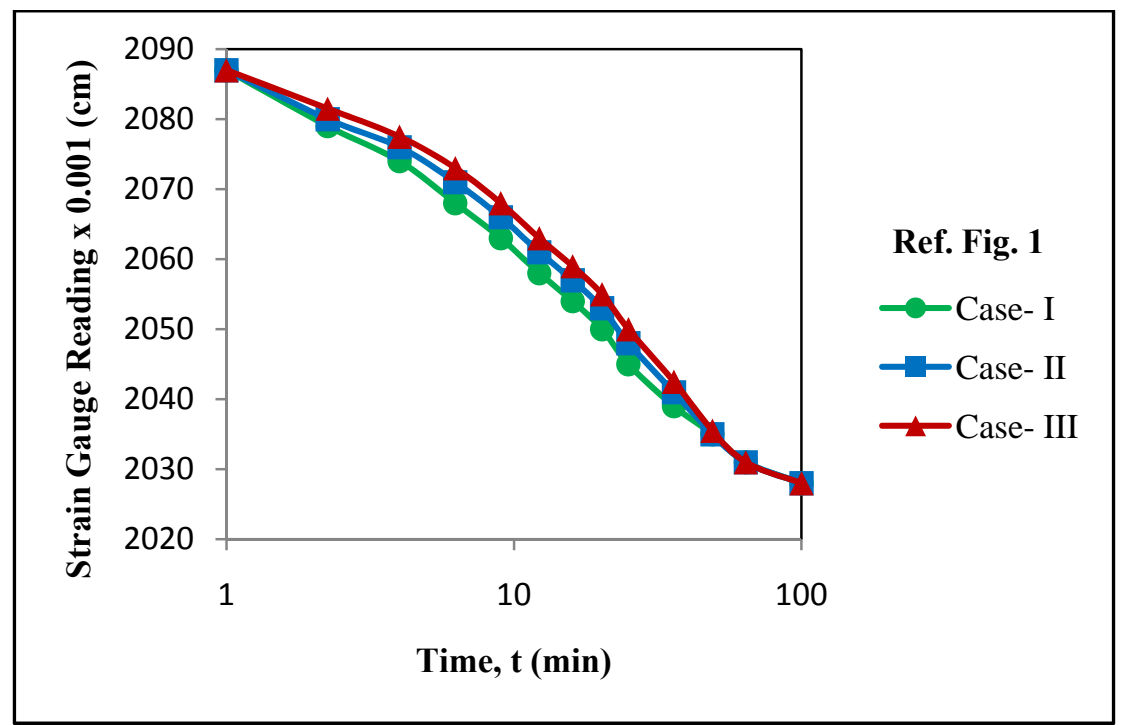

Fig. 4. Vertical settlement with respect to time with different flow conditions under 3-D consolidation test

\section{DISCUSSIONS}

Effect of anisotropic flow of water on three-dimensional consolidation behaviour of silty-clay soil is discussed herein. Compressibility and rate of consolidation of silty-clay soil under 1-D and 3-D consolidation conditions are also discussed in this section.

\section{A. Effect of Anisotropic Flow of Water on Three-Dimensional Consolidation Behaviour of Silty-Clay Soil}

Consolidation of soil is largely depend upon the flow of extraction of pore water from the high stressed area to low stressed area. This flow of water is depending upon the type of soil and if soil is anisotropic, then flow of water also will be anisotropic in nature. Simulating field drainage conditions at laboratory consolidation test may help to predict more accurate rate of consolidation.In case of traditional oedometer test, measurements are restrained to vertical direction only and so the rate of extraction of pore water decrease compare to in-situ rate of extraction of pore water. In in-situ conditions there may have different drainage conditions as presented in Fig. 1. Table III presented the variation of void ratio with change of vertical pressure for silty-clay soil tested by newly developed 3-D consolidometer apparatus and it is observed that the changes of void ratios are same for all the three cases, under three different flow conditions. Coefficient consolidation is depending on the drainage conditions of soil as well as vertical and horizontal movements of soil particles. As in traditional oedometer test, onlyvertical drainage and vertical movement of soil particles are considered, and radial flow of water and radial movement of soil particles ignored; it may not be possible to get appropriate values of consolidation characteristics. 
In present three-dimensional consolidation test apparatus shown in Fig. 2, it is possible to control the direction of flow of water and due tothis; it may be possible to replicate the actual flow of water at different field conditions.

\section{B. Compressibility of Soil Under 1-D and 3-D Consolidation Conditions}

Tests have been conducted with silty-clay soil using both traditional 1-D oedometer test apparatus and the newly developed 3-D consolidometer test apparatus under the same ranges of vertical stresses. From Tables IV and V, a trendis observed that the values of compression index $\left(\mathrm{C}_{\mathrm{c}}\right)$ obtained from traditional oedometer test are greater than the values obtained from the present 3-D consolidometertest. The applied stress on the soil sample by both the apparatus are same and corresponding to each applied stress, strain of soil is measured. Considering a full stressed area below the loading plate of presently developed 3-D consolidometertest apparatus, it shows a trend of low compressibility compare to the compressibility results obtained from traditional 1-D oedometer test. From Fig. 4, it is observed that the initial and final settlements are same for all the three cases and different during the process of consolidation. The compression characteristic of the saturated soil may approximately similar in the early stages of consolidation for all the different drainage conditions, and so that the initial surface settlements of the soil with different flow conditionsare of little difference. With the progress of consolidation, the effects of permeability become more prominent and this leads to greater settlements of the soil with greater opening at the outer surface of the sample.Since the value of excess pore water pressure tends to be zero at the end of the consolidation, no more pore water would be extracted at the end of consolidation, thus there is no relationship between the anisotropic flow of water and final surface settlements.

\section{Rate of settlement of soil under 1-D and 3-D consolidation conditions}

The rate of consolidation of soil is proportional to the rate of extraction of pore water from the soil sample. With the extraction of pore water from soil mass, the arrangement of skeleton of soil gets changed and due to which settlement occurs. At the time of rearrangement of soil particles with the extraction of water, it may move in horizontal as well as in vertical direction. But in case of traditional oedometer test, radial flow of pore wateras well as radial movements of soil particles restrained. So the rate of settlement in case of one-dimensional consolidation is much smaller than the rate of in-situ settlement of shallow foundations.Table VI shows the comparison of coefficient of consolidation ( $c_{v}$ )obtained by using the 1-D oedometer testapparatus and newly developed 3-D consolidometer apparatus.Fig. 3 graphically shows the variation of coefficient of consolidation $\left(\mathrm{C}_{\mathrm{v}}\right)$ by using the 3-D consolidometer test apparatus under different flow conditions for different pressure ranges. From Table VI and Fig. 3 it is observed that the rate of settlement is high in case of 3-D consolidation test. From Fig. 3 it is also observed that the Case-I showing high coefficient of consolidation compare to the Case-II and Case-III. The coefficients of consolidation values decrease with the increase of restriction ofthe outward flow of water during the test. Practically in the majority of cases, shallow foundations are subjected to 3-D consolidation conditions under different anisotropic flow conditions.

\section{CONCLUSIONS}

This study concentrates on the consolidation of silty-clay soil at a maximum dry density obtained from standard Proctor compaction test under anisotropic flow conditions. Consolidation test of silty-clay soil of Tripura, India has been performed by using both the traditional one-dimensional consolidation apparatus and presently developed three-dimensional consolidation apparatus. Traditional oedometer shows the consolidation characteristics of soil with only vertical extraction of water and this 1-D flow condition is generally used to represent the actual field consolidations. In this study anisotropic flow conditions are tried to incorporate during the consolidation of soil. Anisotropic flow of water does not have any effect on the initial and the final surface settlement but has a significant effect during the consolidation process. Since the 3-D consolidations allowhorizontal movement of soil particles along with vertical settlement, it shows higher rate of settlement compare to 1-D consolidation. In case of 3-D consolidation tests, with the increase of restriction of flow of water, the rate of consolidation decreases.

\section{REFERENCES}

[1] K. Terzarghi, "Die Berechnung der Durchlassigkeitsziffer des Tones ausdemVerlauf der hydrodynamischenSpannungserscheinungen,” Stiz. Wiss. Math.-naturw. Abt. IIa, 132 Bd., 3. U.4.H., 1923.

[2] M. A. Biot, "General theory of three-dimensional consolidation. Journal of applied physics," American Institute of Physics, Vol. 12, Issue 2, pp. 155-164, 1941.

[3] Z. Ai, and Y. Cheng, "3-D consolidation analysis of layered soil with anisotropic permeability using analytical layer-element method,”ActaMechanicaSolidaSinica, ELSEVIER, Vol. 26, Issue 1, pp. 63-70, 2013.

[4] D. Hwang and M. W.Witczak, "Multidimensional probabilistic consolidation,”Journal of Geotechnical Engineering, ASCE, Vol. 110, No. 8, pp. 1059-1078, 1984.

[5] American Society for Testing and Materials, “ASTM Test method for One-Dimensional Consolidation Properties of soils,” (D 2435801989), pp. 283-287,1989.

[6] T. Lambe, and R. V. Whitman, Soil Mechanics, John Wiley and Sons, Inc., New York, 1969. 


\section{AUTHORS PROFILE}

Arpan Laskar has born on 28-Dec-1988 and obtained B.E.in Civil Engineering from Tripura Institute of Technology, Agartala, Tripura, India in 2011 and M.Tech. in Geotechnical engineering from National Institute of Technology Agartala, Tripura, India in 2013. Presently pursuing his Ph.D. from NIT Agartala, Tripura, India. His area of research is analysis of three-dimensional consolidation settlement. He has published papers in international journals and national conferences. Author has membership in professional society like IGS.

Dr. Sujit Kumar Pal is presently working as Associate Professor in Civil Engg., NIT, Agartala, Tripura, INDIA. Completed BE (Civil Engg.) from REC, Surathkal, Karnataka, INDIA (Presently, NIT, Surathkal) in 1986 and M. Tech (Soil Mech. \& Foundation Engg.) from IIT, Khragpur, West Bengal, INDIA in January, 1993. He has completed his Ph.D (Engg.) from Bengal Engineering and Science University, Shibpur, West Bengal, INDIA (Presently, Indian Institute of Engineering Science and Technology, Shibpur) in January, 2010. He has a wide range of publications in national and international Journals and conferences like, ASCE, SPRINGER, EJGE, IJRET, IGC, DFI etc. His present research areas are soil characterization, soil dynamics, ground improvement, shallow and deep foundations and soil-structure interaction. His teaching experience is more than 30 years and actively engaged in teaching, research and consultancy works. 